\title{
Self-tuned Fuzzy-PD Control for QNET 2.0 Rotary Inverted Pendulum using lab-view
}

\author{
Engr. Amjad Ali, Arbab Nighat
}

\begin{abstract}
An Inverted pendulum is a nonlinear system and broadly utilized as automated arm. The challenge is to balance the pendulum that can rotate in only two ways, either to the positive or to the negative direction \pm 180 Degree. This research work is aiming to design a controller based on self-tuned fuzzy logic and (Fuzzy-PD) for QNET-2.0 Rotary Inverted Pendulum using lab-view. This self-tuned fuzzy $P D$ control is responsible to generate computer based signals for stable outputs and can works on errors. Rotary Inverted pendulum (RIP) is used as real time model where self- tuned fuzzy PD control is applied for stabilization. There are two aspects to the control objectives for the inverted pendulum: swing-up and balance in a typical PD system, the balancing controller is generated using a fuzzy logic controller, instead of the proportional term. the swing-up controller is generated in a standard proportional controller by using a fuzzy logic system, instead of the proportional term. To build Lab-VIEW approaches, a software development technique is used to help programmers produce code that has greater potential to solve a problem as opposed to writing code without a design. This approach also helps make coding more accessible, more flexible, and more changeable. Rotary Inverted pendulum systems were operated and managed by means of the PD module and the Fuzzy PD Module in Lab-VIEW. The fuzzy controllers are added into the system after the design of the standard $P D$ and $P$ controllers. The two types of controllers the fuzzy $P$ and the fuzzy $P-D$, and the common proportional and standard $P D$, are finally implemented and evaluated on the actual inverted pendulum hardware, and also the Control system output is compared between two different control methods.
\end{abstract}

Keywords: Rotary, Inverted Pendulum, Fuzzy Logic, PD control, Self-tuned Fuzzy Controller.

\section{INTRODUCTION}

The Rotary Inverted Pendulum basically exhibits the non-linear behavior therefore its stabilization with different control designs are complex task. Different controls are applied such the proportional, integrator, derivative (PID), Robust control and fuzzy logic design. [1] The dynamics of RIP is shown in Figure.1.

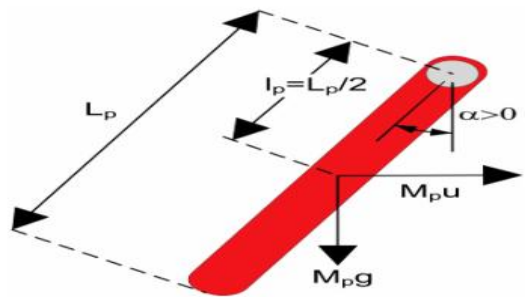

Figure 1. Free Body Diagram of Pendulum [2]

Revised Manuscript Received on February 05, 2020.

* Correspondence Author

Engr. Amjad Ali, Department of Electronics Engineering, Mehran UET Jamshoro, Pakistan. Email: engr.amjad12@gmail.com

Dr. Arbab Nighat, Department of Electronics Engineering, Mehran UET Jamshoro, Pakistan. Email: arbab.nighat@faculty.muet.edu.pk

(c) The Authors. Published by Blue Eyes Intelligence Engineering and Sciences Publication (BEIESP). This is an open access article under the CC BY-NC-ND license (http://creativecommons.org/licenses/by-nc-nd/4.0/)
Numerous control designs have been done by many researcher [8-10]. The inverted pendulum works on the Newton's 3rd law of motion. [9]. The main objective of this research work is to design the fuzzy based PD control for swing-up and balancing position for rotary inverted pendulum. The model contains pivoted base having the narrow steel pole of the pendulum, indicated as rotate point and it is mounted on a heading. The pendulum rotational angle " $\alpha$ " and arm angle " $\theta$ " moves on a level plane and has to stabilize the pendulum. To balance the pendulum in equilibrium state, a PD fuzzy controller is utilized. The zero reference point of pendulum's pole is connected to one of main encoder i.e. potentiometer (pot) of the model. Accordingly, due to varying positions, different voltages are produced that are compared to zero reference point voltage. Therefore, a proper control signal is generated. [12]

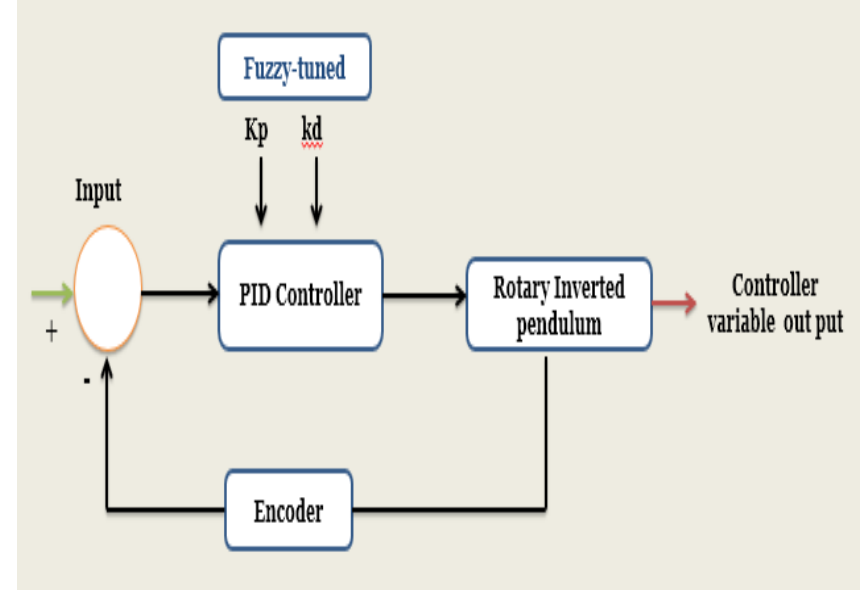

Figure 2. Proposed control block diagram.

\section{A.LAB-VIEW}

Lab-VIEW is an integral part of virtual instrumentation as it provides a developer-friendly application development environment specifically designed to support the engineers. [3] Lab-VIEW provides powerful features making it easy to connect to a wide range of hardware and other software One of the most powerful features Lab-VIEW provides the interactive programming experience to engineers and scientists through knobs, buttons, dials, and graphs. One can configure front panels to imitate conventional instrument control panels, build personalized test panels, or visually display process control and operation.

The resemblance between common flow charts and graphic systems shortens the path of learning correlated with standard languages based on text. [7] 


\section{B. System Kinematics}

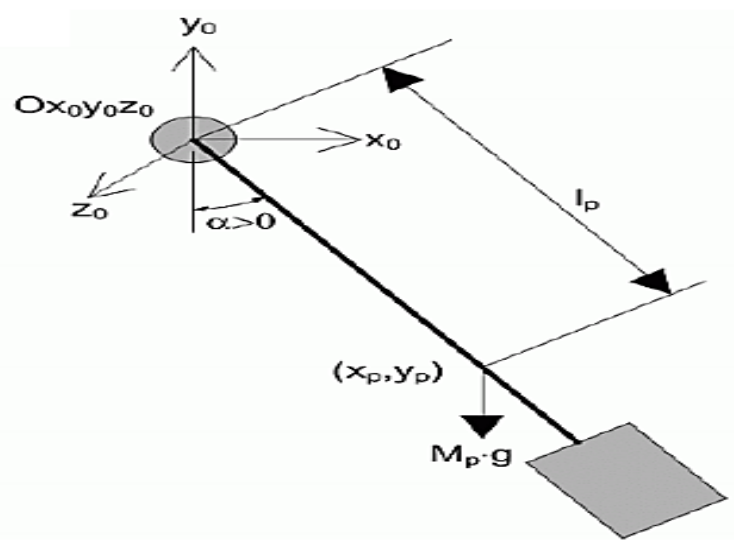

Figure 3.Diagram of free body RIP [11]

$$
\begin{aligned}
& x_{p}=l_{p} \sin (\alpha(t)) \\
& y_{p}-l_{p} \cos (\alpha(t))
\end{aligned}
$$

In same way by derivation of differentiation, get velocities as:

$$
\begin{aligned}
& d x_{p}=l_{p} \cos (\alpha(t))\left(\frac{d}{d t} \alpha(t)\right. \\
& d y_{p}=l_{p} \sin (\alpha(t))\left(\frac{d}{d t} \alpha(t)\right.
\end{aligned}
$$

\section{Potential Energy: (P.E)}

$\boldsymbol{y}_{\boldsymbol{p}}$ is used to find the potential energy, $U t$ :

$$
U t(\alpha)=\operatorname{Mp} g \operatorname{Lp}(1-\cos (\alpha(t)))
$$

Pendulum position at down word position, $\alpha=0$,

$$
U_{t}(\alpha=0)=0 \mathrm{~J}
$$

Pendulum is at the upright position, $\alpha=\pi$,

$U_{t}(\alpha=\pi)=\operatorname{Mpg} L p$

\section{Kinetic Energy: (K.E)}

$T_{t}$ is used for pendulum rotation.

$$
T_{t}=\frac{1}{2} J p \alpha^{2}
$$

Where $\alpha \&$ is rotational velocity of inverted pendulum.

\section{E. Pendulum Inertial Movement}

To find out inertia frequency of pendulum. When swing freely so, [2].

$$
T_{p}=0, \alpha=0
$$

The set-up equation is non-liner, to linearize the equation sin $(\alpha)=\alpha$ when the small value of $\alpha$.

$$
J_{p}(\ddot{\alpha})+M_{p} \mathrm{~g} L_{p} \alpha=0
$$

Use the same initial condition

$$
\text { to resolve the linearized equation. }
$$

$$
\begin{aligned}
& \alpha(0)=\alpha_{0} \\
& \dot{\alpha}(0)=0
\end{aligned}
$$

then, the Laplace transform of the linearized equation:

$$
J_{p}\left(s^{2} \alpha(s)-\alpha_{0}\right)+M_{g} g L_{p} \alpha(s)=0
$$

$$
\alpha(S)=\frac{\alpha_{0} J_{p}}{M_{p} g L_{p} S+J_{p} S^{2}}
$$

Therefore, the frequency $\mathrm{f}$

$$
f=2 \pi \sqrt{\frac{M_{p} g L_{p}}{J_{p}}}
$$

Rearranging equation (7) we get moment of inertia $J_{p}$ :

$$
J_{p}=\frac{M_{p} g L_{p}}{4 \pi^{2} f^{2}}
$$

While putting system parameter values of $\frac{M_{p} g L_{p}}{4 \pi^{2} f^{2}}$ in equation no.14 then value of $\boldsymbol{J}_{\boldsymbol{p}}$ should be $\left(0.0769 \mathbf{k g} \cdot \mathrm{m}^{2}\right)$.

\section{METHODOLOGY}

Main QNET 2.0 Rotary Pendulum features:

- Compact and complete rotary servo system for NI ELVIS II (+)

- $\quad 18 \mathrm{~V}$ direct-drive brushed DC motor

- Encoders mounted on DC motor and pendulum

- Built-in PWM amplifier

- $\quad$ Build-in PCI connector for NI ELVIS II (+)

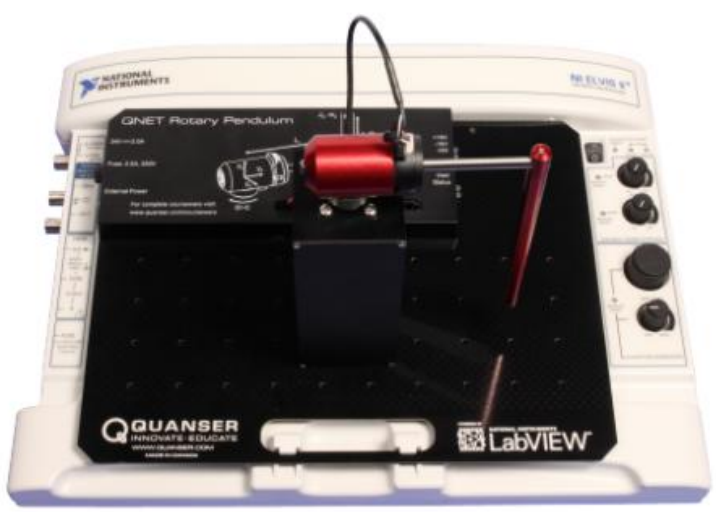

Figure 4. Quanser QNET 2.0 with NI ELVIS II Board [5]

The main QNET Rotary Pendulum's parameters are shown in Table 1. The QNET Rotary Pendulum includes a direct-drive $18 \mathrm{~V}$ brushed DC motor housed in a solid aluminum frame. The single-ended optical shaft encoders used to measure the angular position of the DC motor and pendulum of the QNET Rotary Pendulum. The complete specification sheet of the E8 P optical shaft encoder is given in E8P Data Sheet.

Table 1. Rotary Inverted Pendulum Specification.

\begin{tabular}{|l|c|l|}
\hline Symbol & Description & Value \\
\hline Vnom $_{m}$ & VOLTAGE & $18_{\mathrm{v}}$ \\
\hline$R_{m}$ & TERMINAL RESISTANCE & 8.4 \\
\hline$K_{t}$ & TORQUE CONSTANT & $0.043_{\mathrm{nm} / \mathrm{a}}$ \\
\hline$J_{p}$ & $\begin{array}{c}\text { PENDULUM MOMENT } \\
\text { OF INERTIA. }\end{array}$ & $1.88_{\mathrm{kg} . \mathrm{m} 2}$ \\
\hline$K_{m}$ & MOTOR BACK EMF & $0.043_{\mathrm{v} /(\mathrm{rad} / \mathrm{s})}$ \\
\hline$J_{m}$ & ROTO INERTIA & $4.1 \times 10^{-6} \mathrm{kgm} 2$ \\
\hline$L_{m}$ & ROTORINDUCTANCE & $1.17_{\mathrm{mh}}$ \\
\hline$M_{h}$ & MODULE & $0.017_{\mathrm{kg}}$ \\
& ATTACHEMENT HUB MASS & \\
\hline
\end{tabular}




\begin{tabular}{|l|c|l|}
$R_{h}$ & $\begin{array}{c}\text { MODULE } \\
\text { ATTACHEMENT HUB RADIOUS }\end{array}$ & $0.0112^{\mathrm{m}}$ \\
\hline $\mathrm{Jh}$ & MODULE & $0.7 \times 10^{-6} \mathrm{kgm} 2$ \\
& ATTACHEMENT MONENT & \\
\hline$M_{r}$ & ARM MASS & $0.096_{\mathrm{kg}}$ \\
\hline$L_{r}$ & ARM LENGTH & $0.086_{\mathrm{m}}$ \\
\hline$M_{p}$ & PENDULUM LINK MASS & $0.023_{\mathrm{kg}}$ \\
\hline$L_{p}$ & PENDULUM LINK LENGTH & $0.128_{\mathrm{m}}$ \\
\hline
\end{tabular}

The proposed fuzzy based PID control shows in Figure.5. the parameters for Rotary Inverted pendulums is designed in Lab-view and then send to the encoders to shows the position of pendulum, Arm angle, and Energy of pendulum.

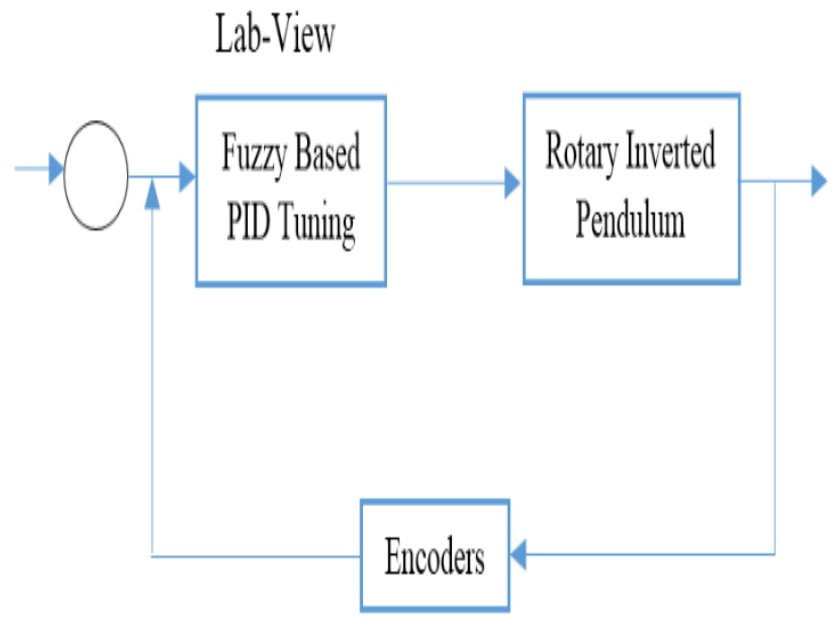

Figure 5. Block Diagram of Fuzzy Tuning of Rotary Inverted Pendulum.

The QNET Rotary Pendulum provides communication interface with the NI ELVIS II (+). The interaction between the different system components on the QNET RIP is illustrated that the NI ELVIS II (+) is interfaced to the PC or laptop via USB link with QNET Rotary Pendulum. The NI-ELVIS II (+) block reads the angular encoder inputs and commands the power amplifier that drives the DC Motor.

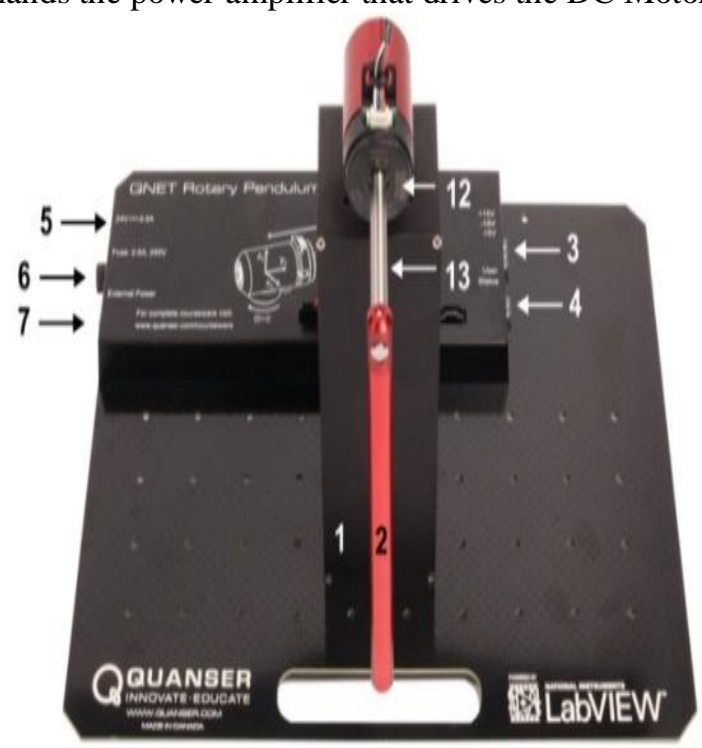

Figure 6. Front view QNET-2.0 RIP

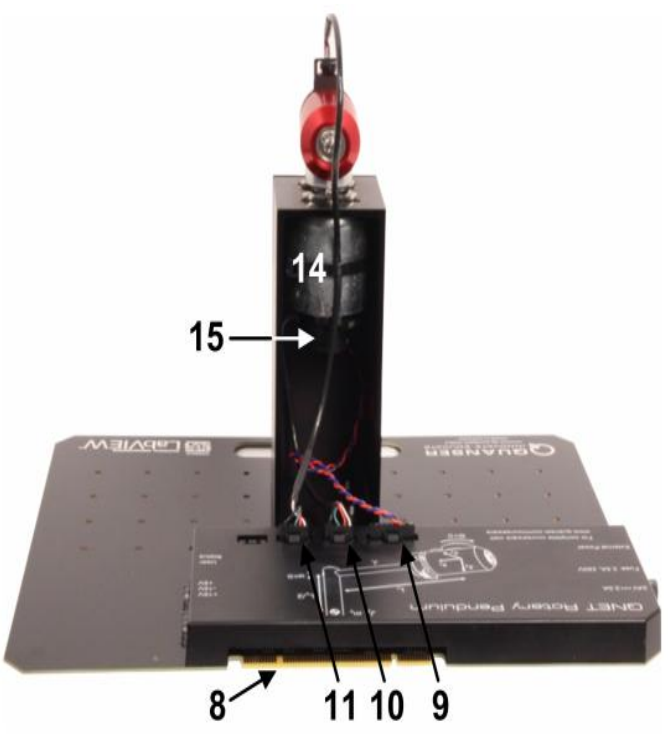

Figure 7. Rear view QNET-2.0 RIP. [4]

The controller is designed and applied to RIP. The objective of fuzzy based tuning of PID control is to stable the RIP at up position and keep balance in upward direction. Therefore, two controls are designed; one for swing up control and another is for balance position as shown in figure-8. The swing-up controller produces the torque associated with a pendulum base arm invert the pendulum in upward direction. When a pendulum is swing-up, the balance controller expects to start its controlling for balance that position.

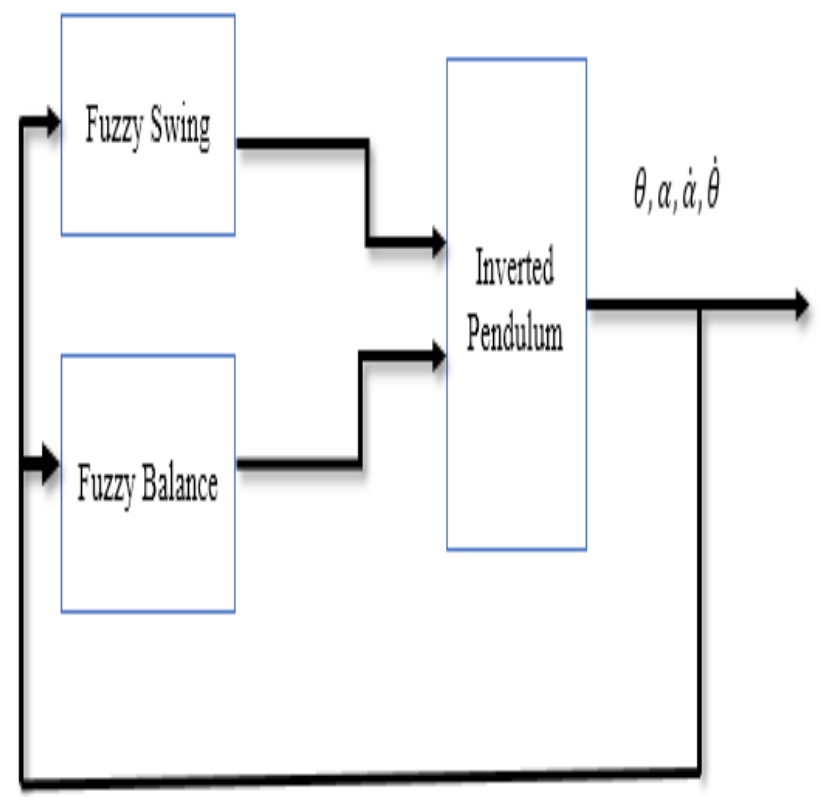

Figure 8. Block Diagram of Swing up and balance Controller

Note that in Figure.8. for fuzzy swing-up controller, energy (E) is taken as input quantity while gain $(\mu)$ is considered as output. The fuzzy $\mathrm{P}$ controller is to create an initial thrust when the pendulum is downwards; desired gains are achieved as output. pendulum's angle $(\alpha)$ and angular velocity $\left(\alpha^{*}\right)$ are the input quantities for

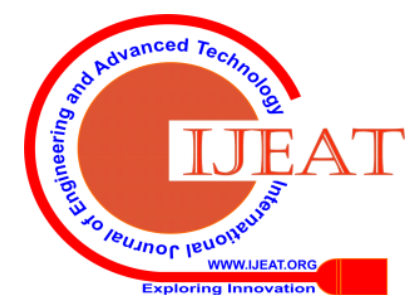


PD-fuzzy balance controller that gives output quantity proportional gain $\left(k_{-}(p, \alpha)\right)$. When pendulum angle and angular velocity are negative or positive, small power is given to DC motor for balancing controller. If angle and angular velocity are reciprocals of one another like angle is negative and angular velocity is positive or the opposite, then the gain will be supplementary. The designing of fuzzy rules for Swing-up Controller are given to calculate the energy of pendulum, so the energy is constant when the arm is balanced at $30.368 \mathrm{mj}$.

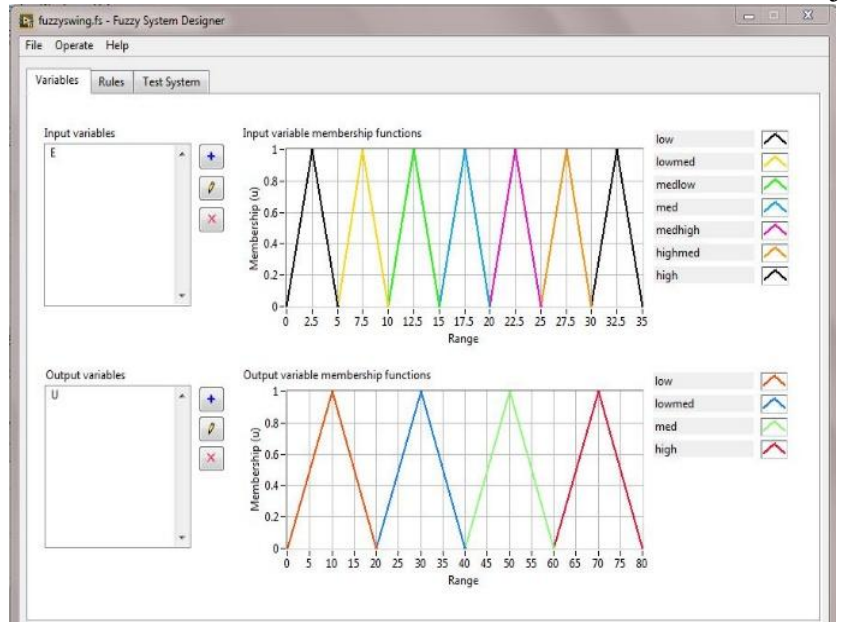

Figure 9. Input/output Membership function for Swing up Controller

Table.2. Fuzzy If- then rules of Swing-up control.

\begin{tabular}{|c|l|}
\hline 1) & IF 'Input E' IS 'LOW' THEN 'Output $\mu$ ' IS 'HIGH'. \\
\hline 2$)$ & $\begin{array}{l}\text { IF 'Input E' IS 'LOW,MED' THEN 'Output } \mu \text { ' IS } \\
\text { 'MED'. }\end{array}$ \\
\hline 3$)$ & $\begin{array}{l}\text { IF 'Input E' IS 'MED,LOW' THEN 'Output } \mu \text { ' IS } \\
\text { 'MED' }\end{array}$ \\
\hline 4$)$ & $\begin{array}{l}\text { IF 'Input E' IS 'MED' THEN 'Output } \mu \text { ' IS } \\
\text { 'LOW,MED'. }\end{array}$ \\
\hline 5) & $\begin{array}{l}\text { IF 'Input E' IS 'MED,HIGH' THEN 'Output } \mu \text { ' IS } \\
\text { 'LOW,MED' }\end{array}$ \\
\hline 6$)$ & $\begin{array}{l}\text { IF 'Input E' IS 'HIGH,MED' THEN 'Output } \mu \text { ' IS } \\
\text { 'LOW,MED' }\end{array}$ \\
\hline 7$)$ & IF 'Input E' IS 'HIGH' THEN 'Output $\mu$ ' IS 'LOW' \\
\hline
\end{tabular}

Designing of Fuzzy Rules for Balance Control in which Arm

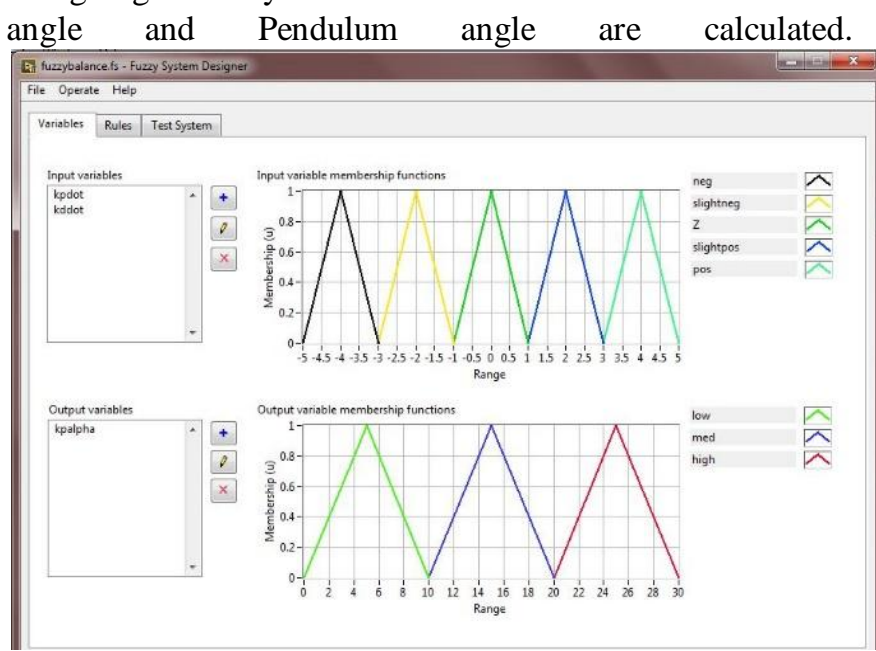

Figure 10. Input/output membership functions of Balancing Control.
Table.3. Fuzzy If- then rule for Balancing Control.

\begin{tabular}{|c|c|}
\hline 1) & $\begin{array}{c}\text { If } k p \text {, dot is 'Neg' and } \mathrm{Kd} \text {, dot is 'Neg' then } K_{p, \alpha} \text { is } \\
\text { LOW. }\end{array}$ \\
\hline 2) & If $k p$, dot is 'Neg' and $\mathrm{Kd}$, dot is ' $\mathrm{Z}$ ' then $K_{p, \alpha}$ is MID. \\
\hline 3) & $\begin{array}{c}\text { If } k p \text {, dot is 'Neg' and Kd, dot is 'Pos' then } K_{p, \alpha} \text { is } \\
\text { HIGH }\end{array}$ \\
\hline 4) & $\begin{array}{l}\text { If } k p \text {, dot is 'Slight Neg' and Kd, dot is 'Neg' then } \\
K_{p, \alpha} \text { is HIGH. }\end{array}$ \\
\hline 5) & $\begin{array}{l}\text { If } k p \text {, dot is 'Slight Neg' and Kd, dot is ' } Z \text { ' then } K_{p, \alpha} \text { is } \\
\text { HIGH }\end{array}$ \\
\hline 6) & $\begin{array}{c}\text { If } k p \text {, dot is 'Slight Neg' and Kd, dot is 'Pos' then } K_{p, \alpha} \\
\text { is HIGH. }\end{array}$ \\
\hline 7) & $\begin{array}{c}\text { If } k p \text {, dot is ' } Z \text { ' and } \mathrm{Kd} \text {, dot is 'Neg' then } K_{p, \alpha} \text { is } \\
\mathrm{HIGH}\end{array}$ \\
\hline 8) & If $k p$, dot is ' $\mathrm{Z}$ ' and $\mathrm{Kd}$, dot is ' $\mathrm{Z}$ ' then $K_{p, \alpha}$ is HIGH. \\
\hline 9) & If $k p$, dot is ' $\mathrm{Z}$ ' and $\mathrm{Kd}$, dot is 'Pos' then $K_{p, \alpha}$ is HIGH \\
\hline 10) & $\begin{array}{c}\text { If } k p \text {, dot is 'Slight Pos' and Kd, dot is 'Neg' then } K_{p, \alpha} \\
\text { is HIGH. }\end{array}$ \\
\hline 11) & $\begin{array}{l}\text { If } k p \text {, dot is 'Slight Pos' and Kd, dot is ' } \mathrm{Z} \text { ' then } K_{p, \alpha} \text { is } \\
\text { HIGH. }\end{array}$ \\
\hline 12) & $\begin{array}{c}\text { If } k p \text {, dot is 'Slight pos' and Kd, dot is 'Pos' then } K_{p, \alpha} \\
\text { is HIGH. }\end{array}$ \\
\hline 13) & $\begin{array}{c}\text { If } k p \text {, dot is 'Pos' and } \mathrm{Kd} \text {, dot is 'Neg' then } K_{p, \alpha} \text { is } \\
\mathrm{HIGH}\end{array}$ \\
\hline 14) & If $k p$, dot is 'Pos' and $\mathrm{Kd}$, dot is ' $\mathrm{Z}$ ' then $K_{p, \alpha}$ is MID. \\
\hline 15 & If $k p$, dot is 'Pos' and $\mathrm{Kd}$, do \\
\hline
\end{tabular}

Figure.9 Shows Input/output Membership function for Swing up Controller and Fuzzy If- then rule for Swing-up controller is shown in Table-2. Similarly, Figure.10 is showed Input/output Membership function for balance control and fuzzy If-then rule for Balancing Control are showing in Table 3.

\section{RESULT AND DISCUSSION}

The execution of control strategy that has been discussed in this research work obviously involves hardware components. The main components comprising the QNET Rotary Pendulum are labeled in Figure 6, and Figure 7. System states $\alpha, \dot{\alpha}, \theta, \dot{\theta}$ are responsible to read data from sensors, after hardware is all set and compatibility interface is built between NI Lab-view. These states are then feed to control switch for determining which controller is needed whether balance or swing, in result equilibrium is achieved shows in Figure 11. the Lab-View Controller where reading sensor data and measuring quantities arm angle ( $\theta$ in radians) and link angle ( $\alpha$ in radians). In addition, Figure 12 and 13 signify Lab-View sub-system of Swing controller and balancing controller. 


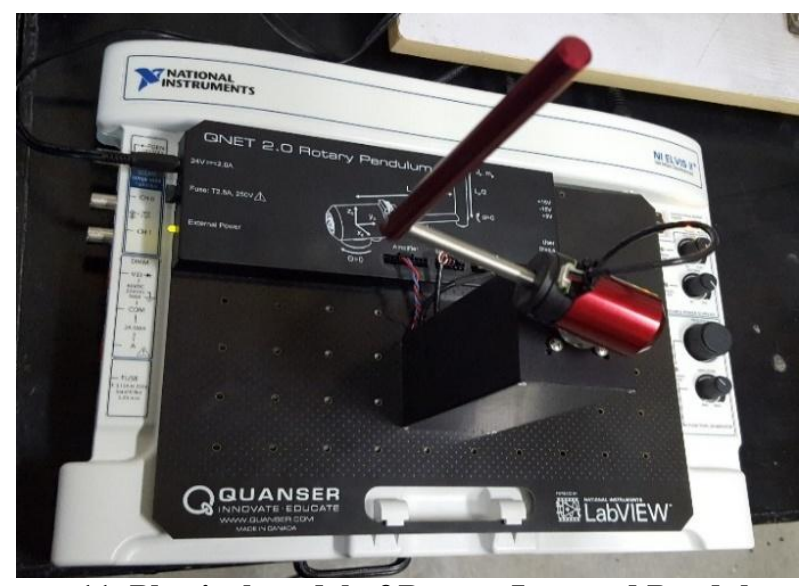

Figure 11. Physical model of Rotary Inverted Pendulum at swing-up and balance position.

The different blocks in Lab-view is showing in Figure-12. Similarly, in Figure-13, different blocks related to balancing controller is shown.

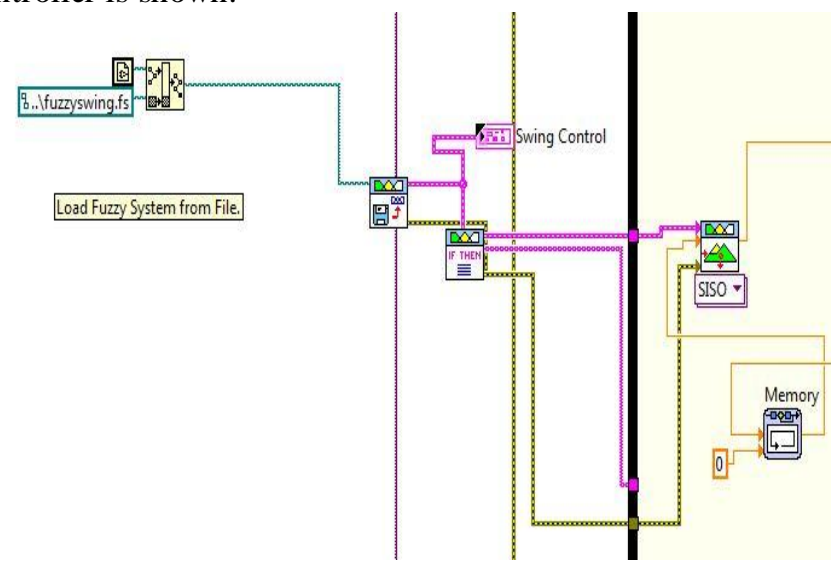

Figure 12. Blocks related to swing- up control in Lab-View.

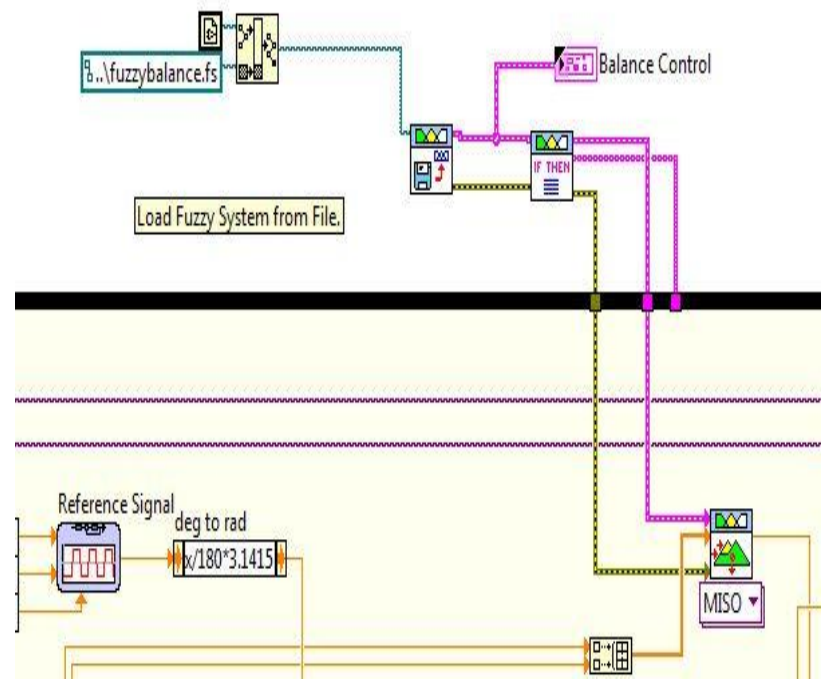

Figure 13. Blocks related to Balance Control in Lab-view. The values processed by control switch to decide which controller should trigger for proper stabilizing rotary inverted pendulum. Swing control calculates the energy, then it is taken to the next step where linear acceleration is appropriately estimated so that the pendulum comes $\mathrm{s}$ in upright position having voltage output for DC motor.

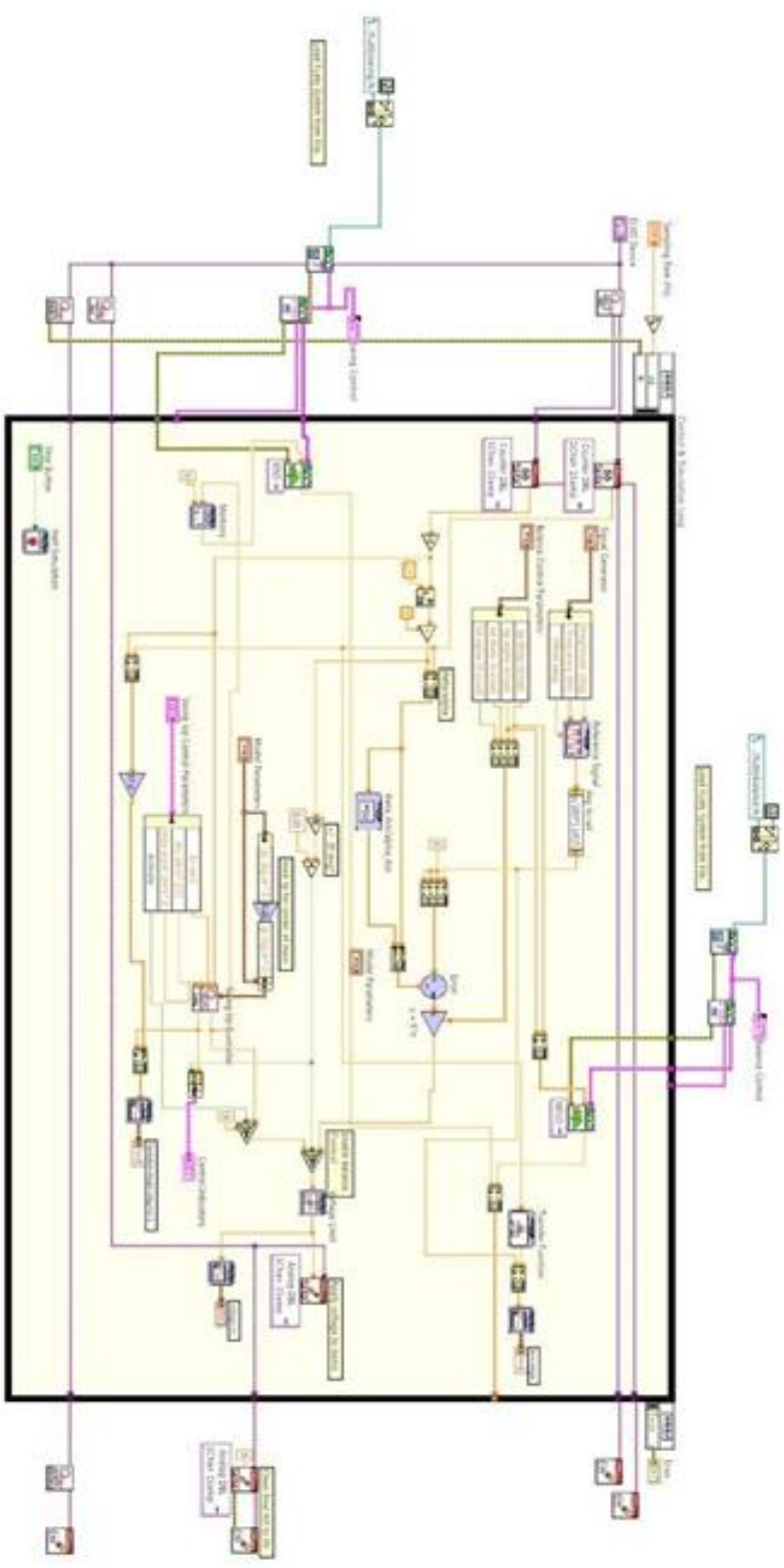

Figure 14. Fuzzy PD Controller in Lab-view

The proposed fuzzy-PD control is compared with existing PD Controller in Lab view in Figure.14.

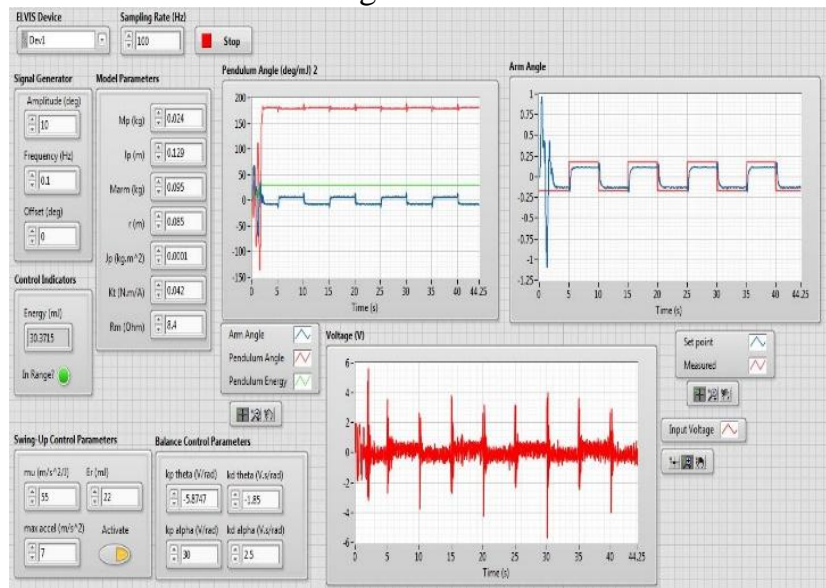

Figure 15. Front panel using existing PD Controller

Published By:

Blue Eyes Intelligence Engineering 

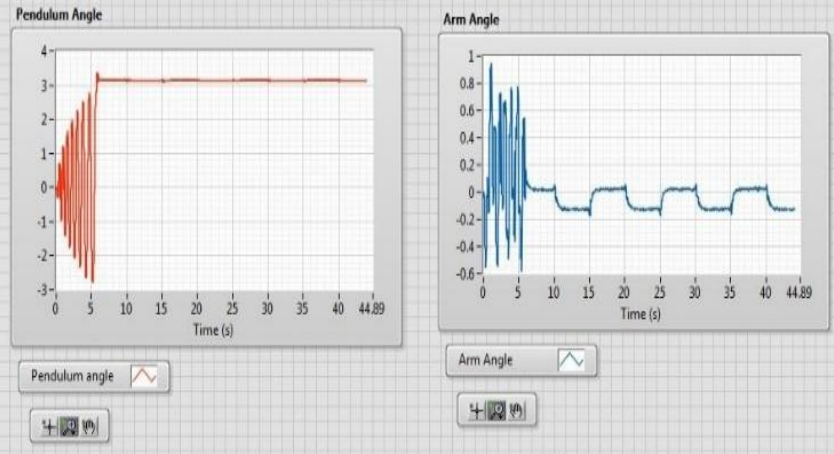

Figure 16. Pendulum Angle and Arm Angle in Existing PD Controller

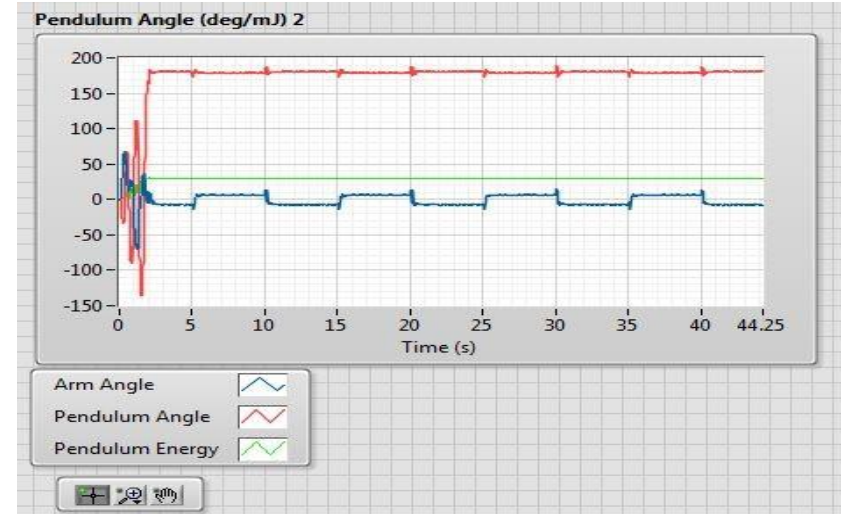

Figure 17. Pendulum Angle (red), Arm angle (blue) and Energy (green) using Fuzzy tuned PD Controller

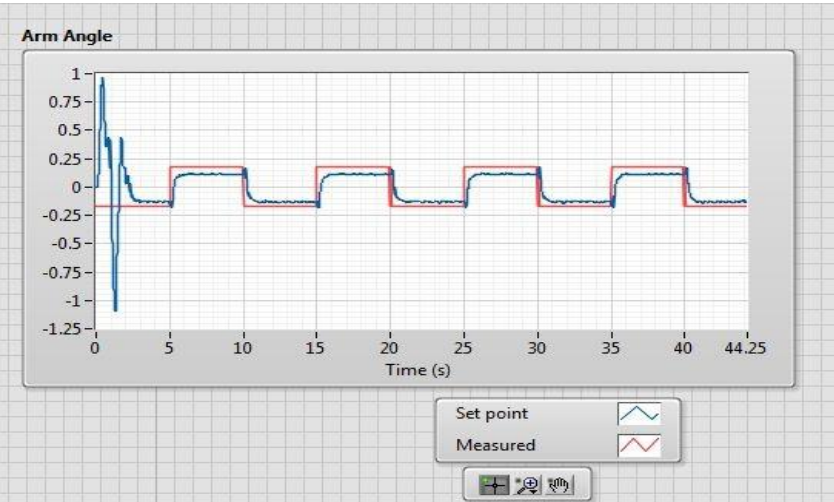

Figure 18. Arm angle and Set point using Fuzzy tuned PD Controller

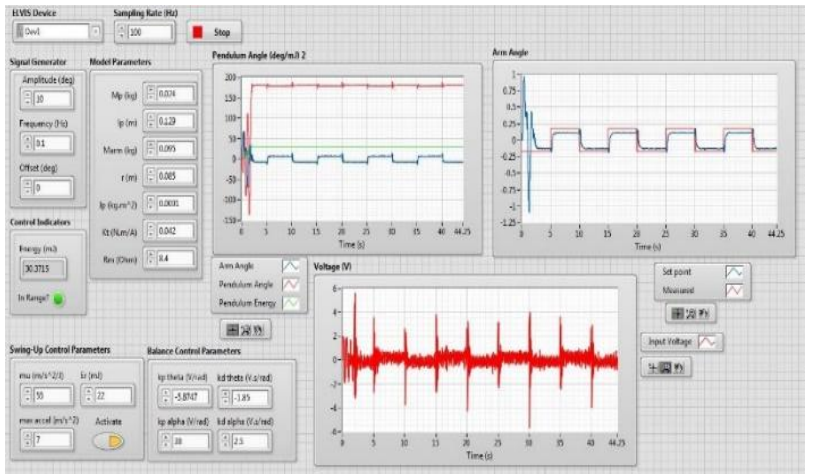

Figure 19. Fuzzy Tuned PD control Front panel

After analyzing the results, it can be stated that initially the pendulum takes more time for Stabilization; whereas, it took less time Stabilization. The Comparison of the two controls is shown in Table 4.
Table.4. Comparison of Existing PD and Tuned Fuzzy PD Controller.

\begin{tabular}{|c|l|l|l|l|c|c|c|}
\hline Controller & $\begin{array}{c}\text { Total } \\
\text { Swing } \\
\text { up time }\end{array}$ & $\begin{array}{c}\text { Arm } \\
\text { Amplitude }\end{array}$ & $\begin{array}{c}\text { Pendulum } \\
\text { Energy }\end{array}$ & $\begin{array}{c}\text { Arm Angle } \\
\text { during } \\
\text { Max. } \\
\text { Swing }\end{array}$ & $\begin{array}{c}\text { Voltage } \\
\text { during } \\
\text { Transient } \\
\text { position }\end{array}$ & $\begin{array}{c}\text { Voltage } \\
\text { After Stable } \\
\text { Position }\end{array}$ & $\begin{array}{c}\text { Pendulum } \\
\text { Angle } \\
\text { (Inverted) }\end{array}$ \\
\hline $\begin{array}{c}\text { Existing } \\
\text { PD }\end{array}$ & $5 \mathrm{Sec}$ & $10^{\circ}$ & 30.370 & -0.4 to 0.4 & -2.5 to 3.5 & -0.75 to 0.75 & $180^{\circ}$ \\
\hline $\begin{array}{c}\text { Fuzzy } \\
\text { Tuned PD }\end{array}$ & $2 \mathrm{sec}$ & $10^{\circ}$ & 30.370 & -1 to 1 & -3.5 to 5.5 & -0.5 to 0.5 & $180^{\circ}$ \\
\hline
\end{tabular}

\section{CONCLUSION}

The aim of this research is to allow use of the Fuzzy Logic Control based controller to develop the inverted pendulum device control algorithm. All the mechanisms and ideas behind this type of controller were well known. Two fuzzy based PD control techniques are proposed and simulated for QNET-2.0 Rotary Inverted pendulum. These controllers are implemented in Lab-VIEW. The fuzzy logic controller was designed using Fuzzy System Designer from Lab-VIEW. The Fuzzy Logic Control + rule-based controller was selected as the alternate system that can be used to modify the PID controller, as it is interface with hardware and on-line control for efficient system. Lastly, a comparative analysis took place to compare the Fuzzy-PD controller and existing PD controller. After experiments and comparisons of both, it is concluded that, fuzzy-PD gave smaller steady state error and faster settling time than conventional PD controller. Fuzzy PD controller takes less time for Balancing so the concluding with the result that fuzzy- PD controller was more efficient and successful controller than existing PD controller. While conclusion the results, the PD controller balance the pendulum in five seconds, while Fuzzy PD Controller took two seconds to balance the QNET 2.0 Rotary Inverted Pendulum.

\section{ACKNOWLEDGMENT}

The authors of this research would like to thank Department of Electronics Engineering, Mehran UET, Jamshoro, Pakistan for their technical support in providing us Instrumentation \& Control Laboratory.

\section{REFERENCES}

1. Yasar Beceriklia, B. Koray Celikb, "Fuzzy control of inverted pendulum and concept of stability using Java application", International journal on mathematical and computer modelling, 2014.

2. Instructor workbook Qnet 2.0 Rotatory Pendulum Board for NI ELVIS, Developed by Quanser

3. National Instruments, "LabVIEW Course LV1 \& LV2", 2011.

4. Quanser.Qnet practical control guide 2016

5. Quanser.Qnet inverted pendulum control laboratory manual 2016

6. www.ni.com /white-paper/4752/en

7. Yen, J., R. Langari, and L. A. Zadeh, eds. 1995. Industrial Applications of Fuzzy Logic and Intelligent Systems. Piscataway, NJ: IEEE Press.

8. Kasruddin , A. N., Modeling and Controller Design for an Inverted Pendulum System, Master Thesis, Faculty of Electrical Engineering, Universiti Teknologi Malaysia.

9. Jain, T. and Nigam, M. J., Optimization of Pd-Pi Controller Using Swarm Intelligence, 2008, Journal Of Theoretical And Applied Information Technology.

10. Astrom, K. J. and Furuta, K., 2000, Swinging up a Pendulum by Energy Control, Automatica. 
11. N.S. Nise. Control systems engineering 6th edition. John Wiley \& Sons, Inc. 2011

12. Devendra Rawat, Jyoti Ohri, "Modeling and Simulation for Optimal Control of Inverted Pendulum using LabVIEW", Proceedings of National Conference on Nanomaterial and Instrumentation (NCNI-2014), NIT Kurukshetra, pp. 110, March 9- 10,2014.

\section{AUTHORS PROFILE}

Engr. Amjad Ali Abbasi is an Electronic Engineer with two years' research experience at Undergraduate level. Currently, he is doing Masters of Engineering (ME) from Mehran UET, Jamshoro, Sindh, Pakistan. His area of research is in Automation \& Control systems.

Dr. Arbab Nighat Kalhoro has research interests in Control Systems. She is presently serving as an Associate Professor at Department of Electronic Engineering, Mehran University of Engineering and Technology (MUET), Jamshoro, Sindh, Pakistan. 